\title{
VARIAÇÃO NO PORTUGUÊS TIKUNA: UM ESTUDO COM BASE NA CONCORDÂNCIA VERBAL DE PRIMEIRA PESSOA E DE /S/ EM POSIÇÃO DE ONSET1
}

\author{
VARIATION IN TIKUNA PORTUGUESE: A STUDY BASED ON THE VERBAL \\ CONCORDANCE OF FIRST PERSON AND OF /S/ IN ONSET POSITION
}

\author{
Ligiane Pessoa dos Santos Bonifácio ${ }^{2}$ \\ http://lattes.cnpq.br/0394521363017703
}

Enviado em: 23/09/2020

Aceito em: 30/09/2020

\begin{abstract}
RESUMO: neste artigo, apresentamos um estudo da variação no Português Tikuna, com base na análise das variáveis sociais e linguísticas no uso de um fenômeno morfossintático e um fonético. O objetivo da pesquisa é analisar quais fatores sociais e linguísticos estariam condicionando a variação quanto ao uso da concordância na primeira pessoa do singular (P1) e ao uso de /s/ em posição de onset. O arcabouço teórico fundamenta-se no campo da Sociolinguística e do Contato Linguístico, a partir de trabalhos como os de Weinreich (1953), Chambers (2003) Wolfram (1969), Romaine (1978), Trudgill (1972), Tarallo (2007) entre outros. Os dados referentes aos falantes foram coletados por meio de gravações em áudio e vídeo com vinte e três professores Tikuna. A análise dos dados é feita em termos de frequência e utiliza o método qualiquantitativo, uma vez que, a partir do corpus da pesquisa, há a sistematização e análise estatística das informações, seguindo-se a análise descritiva. O registro e a análise desses fenômenos variáveis têm a intenção de contribuir para a descrição do português falado na região norte do Brasil.

Palavras-chave: Português Tikuna; Variação; Concordância verbal de primeira pessoa; /s/ em posição de onset
\end{abstract}

\begin{abstract}
Tikuna Portuguese, based on the analysis of social and linguistic variables in the use of a morphosyntactic and a phonetic phenomenon. The purpose of the research is to analyze which social and linguistic factors are conditioning the variation regarding the use of first person singular agreement (P1) and the use of /s/ in the onset position. The theoretical framework is based on the field of Sociolinguistics and Language Contact, based on works such as those by Weinreich (1953), Chambers (2003) Wolfram (1969), Romaine (1978), Trudgill (1972), Tarallo (2007) among others. The data relating to the speakers was collected through audio and video recordings with twenty-three Tikuna teachers. Data analysis is done in terms of frequency and uses the qualitative and quantitative method, since, based on the research corpus, there is the systematization and statistical analysis of information, followed by descriptive analysis. The registration and analysis of these variable phenomena are intended to contribute to the description of Portuguese spoken in the northern region of Brazil.
\end{abstract}

Keywords: Tikuna Portuguese; Variation; First person verbal agreement; /s/ in onset position

\footnotetext{
1 Este trabalho faz parte de uma pesquisa que resultou na tese de Doutorado defendida no Programa de Pós-Graduação em Linguística da Universidade Federal do Rio de Janeiro (UFRJ), sob a orientação da professora doutora Marília Lopes da Costa Facó Soares e contou com o apoio financeiro da Fundação de Amparo à Pesquisa do Estado do Amazonas - FAPEAM.

2 Ligiane Pessoa dos Santos Bonifácio possui doutorado em Linguística pela Universidade Federal do Rio de Janeiro (UFRJ), mestrado em Ciências da Linguagem pela Universidade do Sul de Santa Catarina (UNISUL). Especialização em Língua Portuguesa com ênfase em Produção Textual pela Universidade Estadual do Amazonas (UFAM). Graduação em Letras - Língua e Literatura Portuguesa pela Universidade Federal do Amazonas (UFAM). Atualmente, é Professora Adjunta da Universidade Federal do Amazonas.
} 


\section{Introdução}

A heterogeneidade faz parte da realidade das línguas naturais (pelo menos, as línguas que já foram estudadas reiteram essa afirmação). A língua portuguesa falada no Brasil atesta essa realidade. Não é possível conceber que em um território que conta com 8,5 milhões de quilômetros quadrados e com uma população estimada em mais de 212 milhões de habitantes ${ }^{3}$, com um índice ainda elevado de analfabetismo, houvesse um quadro linguístico homogêneo. A diversidade linguística e cultural são partes constitutivas do nosso país, tendo em vista que à época da colonização, já se falavam, segundo Rodrigues (1993), aproximadamente 1,2 mil línguas indígenas, além disso, a origem dos colonizadores e as consequências linguísticas, desse contato heterogêneo, e, posteriormente, também do contato com os africanos, dentre outros imigrantes no decorrer da história brasileira são aspectos que merecem ser considerados.

Apesar de toda a diversidade, ainda é persistente a idealização de um país monolíngue, que conta com uma gramática imutável e que mais se aproxime do português falado em Portugal. O preconceito linguístico, reiterado algumas vezes pela escola e, muitas vezes, pelos meios de comunicação de massa, é um fator que necessita ser combatido. Uma das formas de combater esse preconceito é o estudo científico acerca da diversidade linguística do Brasil, com a descrição e a análise dessa diversidade.

Nesse sentido, conforme Leite e Callou (2002), os estudos acerca da diversidade linguística no Brasil ficaram focados por muito tempo apenas em variantes populares, em forma de glossários regionais e, mais tarde, nos atlas linguísticos regionais, cujo início se deu na década de 1960. Como resultado dessa empreitada, tem-se o Atlas prévio dos falares baianos, o Atlas linguístico de Sergipe, o Esboço de um atlas linguístico de Minas Gerais, o Atlas linguístico da Paraíba, dentre outros. Segundo Cunha e Silva (2015), em 1996, o projeto Atlas Linguístico do Brasil (ALIB) é lançado, reunindo grupos de pesquisas regionais, com o objetivo de apresentar a diversidade da língua portuguesa falada no Brasil, em todas as áreas da gramática. Conforme Leite e Callou (2002, p. 17), a elaboração do ALIB teve o objetivo "fazer um retrato do Brasil, isto é, dar conta da diversidade existente, ou melhor da dialetação do português, a fim de tornar viável a tão complexa delimitação de áreas próprias a cada fenômeno linguístico".

As pesquisas voltadas aos registros do falar do Amazonas ainda se encontram em estado incipiente, e, quando se trata de variedades de português faladas por indígenas, essa incipiência se acentua. Tal fato justifica a investigação e o registro de fenômenos variáveis que ocorrem no português indígena. Por isso, elegemos investigar um fenômeno fonético e um fenômeno morfossintático variável no falar dos professores Tikuna que atuam em comunidades indígenas de São Paulo de Olivença, na região do Alto rio Solimões, no Amazonas.

Em linhas gerais, este trabalho encontra-se estruturado da seguinte forma: além desta seção introdutória, destinada à apresentação do tema estudado, tem-se, a seguir, um breve painel sobre pesquisas envolvendo variedades de português de contato faladas por indígenas no Brasil. A seção seguinte destina-se à exposição dos resultados obtidos, seguida das considerações finais, com o objetivo de traçar as características consideradas relevantes a partir dos resultados. Por fim, apresentam-se as referências utilizadas na elaboração deste trabalho.

\section{Variedades de Português faladas por indígenas no Brasil}

Quanto aos estudos voltados ao português de contato falado por indígenas, o trabalho de Charlotte Emmerich (1984) é um dos pioneiros a empreender tal tarefa no Brasil. Neste trabalho, a pesquisadora analisou as origens do português Xinguano, bem como a forma e a função que essa variedade assume como meio de comunicação interétnica. O estudo de Emmerich defende que a língua de contato do Xingu é caracterizada por três processos: a fatorização, a pidgnização e a

3 Dados obtidos por meio do site do IBGE em 28/09/2020.

https://periodicos.unifap.br/index.php/letras

Macapá, v. 10, n. 1, $1^{\circ}$ sem., 2020 
depidgnização.

Quanto à forma, ao analisar o português de contato falado pelos indígenas do Alto Xingu, a autora elegeu a variável concordância verbal de primeira pessoa do singular, com o intuito de identificar os contextos condicionadores ou inibidores do emprego da marcação de $1^{a}$ pessoa do singular, bem como avaliar como ocorre a fixação da flexão de pessoa verbal no português do Alto Xingu. Conforme a autora, a intensidade do contato figura como o fator que mais favorece o aprendizado de português, acompanhado do contexto cultural nativo, tal como idade e localidade, os quais são, conforme Emmerich, determinantes no processo aquisitivo e na fluência dos indígenas do Alto Xingu. Os resultados evidenciam que, quanto maior for a fluência do falante de português Xinguano, maior será aplicada a regra de concordância.

Cumpre registrar que a variedade do português de contato falada por indígenas do Alto Xingu é, até o momento, a mais estudada, conforme se pode verificar nos trabalhos de Emmerich (1984), Roncarati e Mollica (1997), Emmerich \& Paiva (2009) e Gomes (1997, 2009), por exemplo.

O livro "Variação e aquisição", organizado por Roncarati e Mollica (1997) abarca um conjunto de textos que apresentam análises acerca do português de contato falado por índios da Reserva do Alto Xingu. Por meio dos artigos, podemos verificar o comportamento de regras variáveis em processos de aquisição da linguagem, tanto no âmbito fonético-fonológico, quanto no morfológico, sintático e discursivo.

Na região norte do país, temos alguns trabalhos representativos, como o de Ferreira (2005), que analisa os efeitos do contato linguístico entre o português e a língua indígena Parkatêjê (Timbira); o de Christino (2015), que apresenta aspectos relacionados à concordância de gênero no interior do sintagma nominal no Português Huni-Kuin e o de Ribeiro (2018), que analisa a variedade do português brasileiro falada em Oiapoque/AP pelos oiapoquenses, falantes monolíngues de português; pelos franceses, bilíngues francês-português, bem como pelos não-bilíngues, usuários de francês L1 e português L2; e pelos indígenas, bilíngues kheuól-português, bem como pelos nãobilíngues, usuários de kheuól L1 e português L2. A análise de Ribeiro (2018) focaliza o processo de concordância de número nos itens do sintagma nominal.

O trabalho de Ferreira (2005) apresenta a análise da variedade étnica do português falado por indígenas que residem em aldeias Parkatêjê, localizadas em Marabá, no estado do Pará. Na análise, a pesquisadora considera aspectos fonético-fonológicos, morfossintáticos, lexicais e semânticos dessa variedade étnica do português. Os resultados apontam que a ocorrência de processos de simplificação gera efeitos sobre a fonologia, a morfossintaxe e o léxico da língua Parkatêjê.

Bonifácio (2019) registra e analisa características sonoras e gramaticais do Português Tikuna por meio da análise de dados de fala de professores indígenas, da etnia Tikuna, que moram em comunidades indígenas do município de São Paulo de Olivença, no Amazonas. Os dados evidenciam que o Português Tikuna é uma variedade que surgiu a partir do contato e que tem maior proximidade, no nível morfossintático, da variedade falada pelos nativos do PB, no entanto, guarda íntima relação com a L1 dos falantes (Tikuna) no nível fonético-fonológico, caracterizando assim, uma variedade particular.

A divulgação dos trabalhos relacionados às variedades linguísticas específicas de comunidades indígenas contribui para que se atinja um conhecimento maior e mais profundo sobre a diversidade linguística do Brasil e se combata o preconceito linguístico ainda tão fortemente marcado em nossa sociedade, tal como aponta Amado (2015).

\section{A variação de /s/ em posição de onset}

A maioria dos estudos sociolinguísticos se dedicam a analisar a variação no uso da fricativa /s/ em posição de coda, tendo em vista que no português brasileiro, as consoantes fricativas [s, $\int$, $z, 3]$ participam de pares opositivos que constituem prova da existência de quatro fonemas fricativos coronais na língua, contrariamente ao que ocorre na posição de coda. Nessa posição, a distin- 
tividade entre tais fonemas é neutralizada.

Gomes, Brescancini e Monaretto (2015) afirmam que existe, no PB, o registro de variação em onset de consoantes fricativas, restritas a alguns itens lexicais, como em re[3]istro $\sim \operatorname{re}[z]$ istro e [J] urrasco] $\sim$ [s] urrasco. A esse respeito, Benayon (2010) afirma que essa variação é altamente estigmatizada no $\mathrm{PB}$.

Paiva (1997) afirma que, no português de contato falado pelos índios Xinguanos, /s / e /z/, por exemplo, constituem duas variantes fonéticas para a expressão do mesmo significando. Isso porque, conforme a pesquisadora, a inversão variável do valor do traço de sonoridade em consoantes oclusivas, fricativas e africadas se manifesta como uma característica que marca o português em aquisição como segunda língua pelos índios do Xingu.

Tendo essas pesquisas em mente e assumindo que, no português Tikuna, identificamos outro comportamento de /s/ em posição de onset, o qual se mostra como alofone em distribuição complementar; apresentamos a variação dessa fricativa em posição de onset, no português de contato falado pelos Tikuna, com vistas a evidenciar as variantes fonéticas que se manifestam na fala dos professores Tikuna nesse contexto fonético.

A análise da variação no uso da fricativa /s/ em posição de onset leva em consideração o fator linguístico e os fatores sociais, conforma explicitamos a seguir. .

Para descrever e analisar a variação da fricativa /s/ em posição de onset na fala dos participantes da pesquisa, foram delimitados os seguintes fatores condicionadores (ou inibidores) da variação em estudo: a) fator linguístico: contexto seguinte - vogal alta [i]; vogal média-alta [ $\varepsilon$ ]; vogal média-baixa [e] e vogal baixa [a]; b) fatores sociais: gênero, faixa etária, escolaridade, localidade e grau de fluência.

Abaixo, apresentamos a atuação da variável linguística: Contexto seguinte.

Tabela 1: Atuação da variável linguística contexto seguinte para a pronúncia de / s/ em onset

\begin{tabular}{|c|c|c|c|c|c|c|c|}
\hline \multirow[b]{2}{*}{$\begin{array}{l}\text { Contexto } \\
\text { Seguinte }\end{array}$} & \multicolumn{2}{|r|}{ [s] } & \multicolumn{2}{|r|}{ [s] } & \multicolumn{2}{|r|}{ [ts] } & \multirow[b]{2}{*}{ Total } \\
\hline & $\begin{array}{c}\mathrm{N}^{\mathrm{o}} \text { de } \\
\text { Ocorrên- } \\
\text { cias } \\
\end{array}$ & Frequência & $\begin{array}{c}\mathrm{N}^{\mathrm{o}} \mathrm{de} \\
\text { Ocorrên- } \\
\text { cias }\end{array}$ & Frequência & $\begin{array}{c}\mathrm{N}^{\mathrm{o}} \text { de } \\
\text { Ocorrên- } \\
\text { cias }\end{array}$ & Frequência & \\
\hline Vogal alta [i] & 395 & $75 \%$ & 120 & $23 \%$ & 11 & $2 \%$ & 526 \\
\hline $\begin{array}{l}\text { Vogal média- } \\
\text { alta }[\varepsilon]\end{array}$ & 34 & $79 \%$ & 9 & $21 \%$ & 0 & $0 \%$ & 43 \\
\hline $\begin{array}{l}\text { Vogal média- } \\
\text { baixa [e] }\end{array}$ & 27 & $37 \%$ & 46 & $63 \%$ & 0 & $0 \%$ & 73 \\
\hline Vogal baixa [a] & 15 & $58 \%$ & 11 & $42 \%$ & 0 & $0 \%$ & 26 \\
\hline
\end{tabular}

Quanto aos resultados, dentre as variantes não previstas no PB padrão em relação à fricativa /s/, [s] foi a mais utilizada pelos participantes da pesquisa, com uma frequência de $63 \%$ em posição de abertura de sílaba após vogal média-baixa. Tal fato indica que essa vogal favorece a palatalização da fricativa, sendo esta pronunciada, ainda, com ligeira retroflexão. Por conseguinte, de modo complementar, a variante [ts] foi pronunciada em apenas $2 \%$ no universo de nossa amostra.

O ponto sobre o qual gostaríamos de chamar a atenção diz respeito não tanto à quantidade de ocorrências por fenômeno, mas à quantidade de variantes possíveis no português Tikuna, quanto à variação da consoante fricativa / s / em posição de onset, fato que não é comum em outras variedades do PB.

Em relação à variante [S], um outro fator que merece atenção é que a segunda vogal que mais favoreceu a palatalização da fricativa, acompanhada de ligeira retroflexão, foi a vogal baixa [a]. O fato de, tanto a vogal média-baixa quanto a vogal baixa terem contribuído para a produção dessa variante indica que o ponto de articulação baixo favorece que a articulação da fricativa ocorra com recuo. Já em relação à variante [ts], a vogal alta foi que favoreceu a ocorrência dessa africação.

Abaixo, será apresentada e discutida a atuação das variáveis sociais, gênero, faixa etária, escolaridade, localidade, graus de contato e fluência no comportamento fonético-fonológico do /s/ em posi- 
ção de onset

Em relação à variável diassexual, o /s/ em posição de onset, nos dados do corpus investigado, distribui-se da seguinte forma:

Tabela 2: Índices gerais referentes à variável social gênero para a pronúncia do / s/ em posição de onset

\begin{tabular}{|c|c|c|c|c|c|c|c|}
\hline \multirow[b]{2}{*}{ Gênero } & \multicolumn{2}{|r|}{ [s] } & \multicolumn{2}{|r|}{ [s] } & \multicolumn{2}{|r|}{ [ts] } & \multirow[b]{2}{*}{ Total } \\
\hline & $\begin{array}{c}\mathrm{N}^{\mathrm{o}} \mathrm{de} \\
\text { Ocorrên- } \\
\text { cias }\end{array}$ & Frequência & $\begin{array}{c}\mathrm{N}^{\mathrm{o}} \text { de } \\
\text { Ocorrên- } \\
\text { cias }\end{array}$ & Frequência & $\begin{array}{c}\mathrm{N}^{\mathrm{o}} \mathrm{de} \\
\text { Ocorrên- } \\
\text { cias }\end{array}$ & $\begin{array}{l}\text { Frequên- } \\
\text { cia }\end{array}$ & \\
\hline Masculino & 331 & $67 \%$ & 153 & $31 \%$ & 9 & $2 \%$ & 493 \\
\hline Feminino & 140 & $80 \%$ & 33 & $19 \%$ & 2 & $1 \%$ & 175 \\
\hline
\end{tabular}

Conforme dados expressos na tabela acima, os falantes homens são aqueles que mais utilizam variantes de /s/, em distribuição complementar. As mulheres, por sua vez, apresentam uma frequência quase que exclusiva da variante de prestígio.

O fato de as mulheres preferirem a variante considerada de prestígio pode ocorrer por dois fatores. Primeiramente, conforme Paiva (2013), as mulheres manifestam menos reserva em relação à mídia que os homens. Por serem mais expostas à mídia, tendem a utilizar mais as variantes manifestas ali. Outro fator tem relação com o status. A seguir, apresentamos os índices relativos à variável social faixa etária para a pronúncia do /s/ em posição de onset.

Tabela 3: Índices relativos à variável social faixa etária para a pronúncia do / s / em posição de onset.

\begin{tabular}{|c|c|c|c|c|c|c|c|}
\hline \multirow[b]{2}{*}{ Idade } & \multicolumn{2}{|c|}{$[\mathrm{s}]$} & \multicolumn{2}{|c|}{ [s] } & \multicolumn{2}{|c|}{ [ts] } & \multirow[b]{2}{*}{ Total } \\
\hline & $\begin{array}{l}\mathrm{N}^{\mathrm{o}} \text { de } \\
\text { Ocorrên- } \\
\text { cias }\end{array}$ & $\begin{array}{l}\text { Frequên- } \\
\text { cia }\end{array}$ & $\begin{array}{l}\mathrm{N}^{\mathrm{o}} \text { de Ocor- } \\
\text { rências }\end{array}$ & Frequência & $\begin{array}{l}\mathrm{N}^{\mathrm{o}} \text { de de } \\
\text { Ocorrên- } \\
\text { cias }\end{array}$ & Frequência & \\
\hline $\begin{array}{c}\text { Faixa } 1 \\
(25 \text { a } 40 \text { anos })\end{array}$ & 323 & $96 \%$ & 11 & $3 \%$ & 3 & $1 \%$ & 337 \\
\hline $\begin{array}{c}\text { Faixa } 2 \\
(41 \text { a } 60 \text { anos) }\end{array}$ & 148 & $45 \%$ & 175 & $53 \%$ & 8 & $2 \%$ & 331 \\
\hline
\end{tabular}

Conforme se pode visualizar na tabela acima, a variante fricativa alveolar [s] apresenta maior índice de ocorrência na faixa etária 1 , sendo que os falantes mais jovens realizaram tal variante com uma frequência quase categórica de $96 \%$, já os mais velhos, realizaram com maior frequência a palatal, com ligeira retroflexão [S], com o índice de 53\%.

A frequência mais baixa do uso da variante fricativa palatal, com ligeira retroflexão [s], (3\%) e da africada palatal, com ligeira retroflexão [t\$ (1\%), pelos mais jovens, parece ser indício de um processo de mudança em curso, com a diminuição do uso dessas variantes nas gerações mais novas.

A seguir, apresentamos os índices relativos à variável social escolaridade para a pronúncia do /s/ em posição de onset.

Tabela 4: Índices relativos à variável social escolaridade para a pronúncia do / s / em posição de onset.

\begin{tabular}{|c|c|c|c|c|c|c|c|}
\hline \multirow[b]{2}{*}{ Escolaridade } & \multicolumn{2}{|c|}{ [s] } & \multicolumn{2}{|c|}{ [s] } & \multicolumn{2}{|c|}{ [ts] } & \multirow[b]{2}{*}{ Total } \\
\hline & $\begin{array}{l}\mathrm{N}^{\mathrm{o}} \text { de } \\
\text { Ocor- } \\
\text { rências }\end{array}$ & $\begin{array}{l}\text { Frequên- } \\
\text { cia }\end{array}$ & $\begin{array}{c}\mathrm{N}^{\mathrm{o}} \text { de } \\
\text { Ocorrên- } \\
\text { cias }\end{array}$ & Frequência & $\begin{array}{c}\mathrm{N}^{\mathrm{o}} \mathrm{de} \\
\text { Ocorrên- } \\
\text { cias }\end{array}$ & Frequência & \\
\hline $\begin{array}{l}\text { Ensino Superior } \\
\text { Completo }\end{array}$ & 145 & $82 \%$ & 30 & $17 \%$ & 1 & $1 \%$ & 176 \\
\hline $\begin{array}{l}\text { Ensino Superior } \\
\text { Incompleto }\end{array}$ & 326 & $66 \%$ & 156 & $32 \%$ & 10 & $2 \%$ & 492 \\
\hline
\end{tabular}

No que diz respeito à variável social escolaridade, Votre (2013) enfatiza que a atuação da escola é de preservadora das formas dotadas de prestígio, geralmente negando/refutando as tendências de mudança em curso nas comunidades economicamente menos favorecidas ou localizadas em 
áreas rurais.

Tendo em vista que em muitas pesquisas sociolinguísticas que levam em consideração essa variável, os resultados sustentam a hipótese de que quanto maior a escolaridade do falante, maior a possibilidade de ele utilizar as formas de prestígio, em nosso estudo, elegemos investigar o comportamento fonético-fonológico (e também morfossintático) dos falantes a partir dessa variável.

Os dados revelam que as variantes [s] e [ts] ocorrem com maior frequência entre os falantes com ensino superior incompleto, enquanto os participantes da pesquisa que têm ensino superior completo fazem o uso mais frequente da variante de prestígio [s] $(82 \%)$.

A seguir, apresentamos os índices relativos à variável social localidade para a pronúncia do /s/ em posição de onset.

Tabela 5: Índices relativos à variável social localidade para a pronúncia do / s / em posição de onset.

\begin{tabular}{|c|c|c|c|c|c|c|c|}
\hline \multirow[b]{2}{*}{ Localidade } & \multicolumn{2}{|c|}{$[\mathrm{s}]$} & \multicolumn{2}{|c|}{ [s] } & \multicolumn{2}{|c|}{ [ts] } & \multirow[b]{2}{*}{ Total } \\
\hline & $\begin{array}{c}\mathrm{N}^{\mathrm{o}} \text { de } \\
\text { Ocorrên- } \\
\text { cias }\end{array}$ & Frequência & $\begin{array}{c}\mathrm{N}^{\mathrm{o}} \text { de } \\
\text { Ocorrên- } \\
\text { cias }\end{array}$ & Frequência & $\begin{array}{c}\mathrm{N}^{\mathrm{o}} \text { de } \\
\text { Ocorrências }\end{array}$ & Frequência & \\
\hline $\begin{array}{c}\text { Comunidade } \\
\text { Vendaval } \\
\end{array}$ & 113 & $54 \%$ & 87 & $42 \%$ & 8 & $4 \%$ & 208 \\
\hline $\begin{array}{c}\text { Comunidade } \\
\text { Santa Inês }\end{array}$ & 22 & $71 \%$ & 9 & $29 \%$ & 0 & $0 \%$ & 31 \\
\hline $\begin{array}{c}\text { Comunidade } \\
\text { Otawari }\end{array}$ & 10 & $63 \%$ & 6 & $38 \%$ & 0 & $0 \%$ & 6 \\
\hline $\begin{array}{l}\text { Comunidade } \\
\text { Paranapara I }\end{array}$ & 16 & $16 \%$ & 82 & $84 \%$ & 0 & $0 \%$ & 98 \\
\hline $\begin{array}{c}\text { Comunidade } \\
\text { Santa Terezi- } \\
\text { nha }\end{array}$ & 32 & $89 \%$ & 2 & $6 \%$ & 2 & $6 \%$ & 36 \\
\hline $\begin{array}{c}\text { Comunidade } \\
\text { Vila Inde- } \\
\text { pendente }\end{array}$ & 77 & $99 \%$ & 0 & $0 \%$ & 1 & $1 \%$ & 78 \\
\hline $\begin{array}{l}\text { Sede de São } \\
\text { Paulo de Oli- } \\
\text { vença }\end{array}$ & 39 & $100 \%$ & 0 & $0 \%$ & 0 & $0 \%$ & 39 \\
\hline $\begin{array}{l}\text { Comunidade } \\
\text { Campo Ale- } \\
\text { gre }\end{array}$ & 69 & $100 \%$ & 0 & $0 \%$ & 0 & $0 \%$ & 69 \\
\hline $\begin{array}{c}\text { Torre da } \\
\text { Missão }\end{array}$ & 29 & $100 \%$ & 0 & $0 \%$ & 0 & $0 \%$ & 29 \\
\hline $\begin{array}{l}\text { São Domin- } \\
\text { gos II }\end{array}$ & 31 & $100 \%$ & 0 & $0 \%$ & 0 & $0 \%$ & 31 \\
\hline Santa Clara & 12 & $100 \%$ & 0 & $0 \%$ & 0 & $0 \%$ & 12 \\
\hline $\begin{array}{c}\text { Nova Gali- } \\
\text { leia }\end{array}$ & 4 & $100 \%$ & 0 & $0 \%$ & 0 & $0 \%$ & 4 \\
\hline $\begin{array}{l}\text { Bom Jardim } \\
\text { do Passé }\end{array}$ & 17 & $100 \%$ & 0 & $0 \%$ & 0 & $0 \%$ & 17 \\
\hline
\end{tabular}

Em relação à variável localidade, os dados mostram que os participantes que moram e atuam na comunidade de Paranapara I foram os que mais uso fizeram das variantes não previsíveis no $\mathrm{PB}$, seguidos dos moradores de Vendaval e Santa Inês.

Ao postularmos o fator localidade, nossa intenção era identificarmos se há localidades cujos moradores apresentam variantes que não ocorrem em outras, bem como se a localização geográfica e o contato dos falantes de Tikuna com falantes de Português exerce alguma influência sobre essa variação. Fato, em nossa amostra, confirmado. Tendo em vista que, em comunidades mais próximas dos centros urbanos, como Campo Alegre e Vila Independente, por exemplo, apresentam variação quase nula, contrariamente às aldeias mais afastadas dos centros urbanos, como Parana- 
para I e Vendaval, por exemplo.

Tabela 6: Índices relativos à variável social grau de contato para a pronúncia do / s / em posição de onset

\begin{tabular}{|c|c|c|c|c|c|c|c|}
\hline \multirow{2}{*}{$\begin{array}{c}\text { Grau de } \\
\text { Contato }\end{array}$} & \begin{tabular}{c}
$|c|$ \\
\cline { 2 - 7 } \\
Ocorrên- \\
cias
\end{tabular} & Frequência & $\begin{array}{c}\mathrm{N}^{\mathrm{o}} \text { de } \\
\text { Ocorrên- } \\
\text { cias }\end{array}$ & Frequência & $\begin{array}{c}\mathrm{N}^{\circ} \text { de } \\
\text { Ocorrên- } \\
\text { cias }\end{array}$ & Frequência & \\
\hline Alto & 161 & $99 \%$ & 0 & $0 \%$ & 1 & $1 \%$ & 162 \\
\hline Médio & 209 & $82 \%$ & 37 & $15 \%$ & 8 & $3 \%$ & 254 \\
\hline Baixo & 101 & $40 \%$ & 49 & $59 \%$ & 2 & $1 \%$ & 252 \\
\hline
\end{tabular}

Com base nos pressupostos teóricos aqui adotados, de que a intensidade do contato exerce alguma influência sobre o processo de aquisição de segunda língua é que utilizamos essa variável social em nosso estudo.

Além disso, em estudos realizados em outras comunidades cujos falantes também têm uma língua indígena como sua L1, a intensidade do contato de falantes de PB L2 com falantes de PB L1 tem se relevado um fator importante para a análise dos estágios aquisitivos em que esses falantes se encontram (cf. Emmerich, 1984; Paiva, 1997; Loureiro, 2005).

Nossos dados revelam o que esperávamos, isto é, no grau mais baixo de contato, as variantes [s] e [ts] foram mais produzidas que nos graus médio e alto.

Tabela 7: Índices relativos à variável social fluência para a pronúncia do / s / em posição de onset

\begin{tabular}{|c|c|c|c|c|c|c|c|}
\hline \multirow[b]{2}{*}{ Fluência } & \multicolumn{2}{|c|}{$[\mathrm{s}]$} & \multicolumn{2}{|c|}{ [s] } & \multicolumn{2}{|c|}{ [ts] } & \multirow[t]{2}{*}{ Total } \\
\hline & $\begin{array}{l}\mathrm{N}^{\circ} \text { de } \\
\text { Ocorrências }\end{array}$ & Frequência & $\begin{array}{c}\mathrm{N}^{\circ} \text { de } \\
\text { Ocorrências }\end{array}$ & Frequência & $\begin{array}{l}\mathrm{N}^{\circ} \text { de Ocor- } \\
\text { rências }\end{array}$ & Frequência & \\
\hline Fluência 1 & 127 & $43 \%$ & 159 & $54 \%$ & 10 & $3 \%$ & 296 \\
\hline Fluência 2 & 88 & $85 \%$ & 15 & $15 \%$ & 0 & $0 \%$ & 103 \\
\hline Fluência 3 & 45 & $79 \%$ & 12 & $21 \%$ & 0 & $0 \%$ & 57 \\
\hline Fluência 4 & 155 & $99 \%$ & 0 & $0 \%$ & 1 & $1 \%$ & 156 \\
\hline Fluência 5 & 56 & $100 \%$ & 0 & $0 \%$ & 0 & $0 \%$ & 56 \\
\hline
\end{tabular}

Por meio da variável fluência, pretendeu-se testar e validar (ou refutar) as faixas de fluência postuladas a partir da frequência de ocorrências dos fenômenos selecionados para estudo, seguido de um peso para cada fenômeno, e atribuídas a cada um dos professores Tikuna.

Os resultados das cinco faixas, manifestos na tabela acima, revelam que os falantes que se encontram na base do continuum fazem maior uso das variantes concorrentes da forma padrão, ao passo que os falantes que se encontram nas últimas faixas do continum usam categoricamente a forma padrão do PB. Em termos numéricos, a frequência dos resultados nas faixas 2 e 3 sugere a necessidade de uma amalgação dessas faixas de fluência; fato que também ocorre com as faixas 4 e 5 .

Essa variável mostrou-se de natureza complexa, haja vista que nela manifestam-se mais nitidamente as pressões que as variáveis exercem umas sobre as outras, sendo que a frequência da ocorrência dos fenômenos está relacionada aos contextos socioculturais, como intensidade do contato, ao status etário, à localidade onde os professores atuam (e para onde se deslocaram para estudar, morar, trabalhar etc).

A segmentação das faixas de fluência, apesar da necessidade de amalgamação de algumas delas, é válida por revelar que os professores falantes bilíngues têm diferentes graus de fluência. A depender do grau de fluência do falante, ele vai usar mais as formas alternantes que são estigmatizadas localmente ou vai utilizar mais a forma de prestígio, aproximando-se da variedade padrão do $\mathrm{PB}$ e afastando-se dos condicionamentos da sua L1. 


\section{A variação na concordância de primeira pessoa verbal}

Esta subseção focaliza a variação na concordância verbal de primeira pessoa do singular, com o propósito de identificar os contextos favorecedores ou inibidores do emprego da marcação de primeira pessoa do singular, bem como avaliar a probabilidade de fixação gradual da flexão de pessoa verbal no Português falado pelos professores Tikuna.

A regra de concordância de primeira pessoa verbal no PB é vista como categórica (cf. Lucchesi e Baxter, 2009) e não tem sido alvo de muitos estudos linguísticos. As investigações que focalizam a variação nessa regra de concordância são em número bastante reduzido e analisam elementos característicos de línguas de contato, como, por exemplo, o de Emmerich (1984), que focaliza a língua de contato no Alto Xingu e os de Ferreira (1994), Baxter e Lucchesi (1997), que usam a variação nessa regra de concordância como um dos argumentos para sustentar a tese da existência de crioulização na formação do português brasileiro.

Quanto ao paradigma flexional do PB, Duarte (1995) evidencia que este tem se reduzido a 3 formas: eu trabalho; você/ele ou ela/a gente trabalha; vocês/eles ou elas trabalham. Essa redução ocorre por dois motivos: primeiro, devido à substituição da segunda pessoa do singular pelo pronome você e; segundo, pela substituição da primeira pessoa do plural por a gente. Diante desse cenário e, levando em consideração que a regra de concordância de primeira pessoa do singular é tida como categórica no PB (cf. Emmerich, 1984; Lucchesi e Baxter, 2009), é que a maioria dos estudos sociolinguísticos no Brasil têm se dedicado a analisar a variação de concordância verbal entre nós e a gente (por exemplo: Menon, 2000; Omena, 2003; Tamanine, 2002, 2010; Franceschini, 2011; Mattos, 2013; Vianna e Lopes, 2015); tu e você (por exemplo: Duarte, 1993; Lopes, 2008; Martins, 2010; Scherre et al., 2015); e terceira pessoa do plural eles ou elas (por exemplo: Naro, 1981; Scherre, 1998; Scherre \& Naro, 1997; Vieira, 1997, 2015; Silva, 2005; Scherre, Naro \& Cardoso, 2007; Lucchesi, Baxter e Silva, 2009; Calazans, 2018).

Em nossos dados, identificamos variação no emprego da flexão verbal, tendo a primeira pessoa verbal co-ocorrendo com as formas não marcadas de terceira pessoa do singular e com as formas não marcadas de infinitivo, gerúndio ou particípio. Diante disso, elegemos analisar esse fenômeno em nosso estudo. Em 2018, em comunidades rurais do Amazonas, compostas por indígenas, ainda ocorria essa variação, diferentemente do que postulam muitos pesquisadores em outras regiões do Brasil.

Para descrever e analisar a variação no emprego da primeira pessoa verbal na fala dos professores participantes da pesquisa, foram delimitados os seguintes fatores condicionadores (ou inibidores) da variação em estudo: a) fator linguístico: forma de interação e b) fatores sociais: gênero, faixa etária, escolaridade, localidade, grau de contato e fluência.

Abaixo, apresentamos a atuação da variável linguística: forma de interação.

Tabela 8: Atuação da variável linguística forma de interação para a marcação ou não-marcação de concordância verbal

\begin{tabular}{|l|c|c|l|l|l|l|l|}
\hline \multirow{2}{*}{$\begin{array}{l}\text { Forma de } \\
\text { interação }\end{array}$} & \multicolumn{2}{|l|}{$\begin{array}{l}\text { Presença da marca de } \\
\text { primeira pessoa verbal }\end{array}$} & \multicolumn{2}{|l|}{$\begin{array}{l}\text { Presença de forma não } \\
\text { marcada - terceira pessoa } \\
\text { verbal }\end{array}$} & $\begin{array}{l}\text { Presença de forma não } \\
\text { marcada - infinitivo, gerún- } \\
\text { dio, particípio }\end{array}$ & Total \\
\cline { 2 - 8 } & $\begin{array}{l}\text { Número de } \\
\text { Ocorrên- } \\
\text { cias }\end{array}$ & $\begin{array}{l}\text { Frequên- } \\
\text { cia }\end{array}$ & $\begin{array}{l}\text { Número } \\
\text { de Ocor- } \\
\text { rências }\end{array}$ & Frequência & $\begin{array}{l}\text { Número de } \\
\text { Ocorrên- } \\
\text { cias }\end{array}$ & Frequência \\
\hline Discurso livre & 1195 & $67,2 \%$ & 400 & $22,5 \%$ & 183 & $10,3 \%$ & 1778 \\
\hline $\begin{array}{l}\text { Discurso } \\
\text { reportado }\end{array}$ & 34 & $44,1 \%$ & 41 & $53,2 \%$ & 2 & $2,6 \%$ & 77 \\
\hline
\end{tabular}

Para fins de esclarecimento, concebemos como discurso livre a fala espontânea dos participantes durante o relato de vida ou nas entrevistas. Por exemplo, como nos momentos em que os participantes eram convidados a falarem sobre a vida escolar, a vida profissional deles e eles começavam a tecer comentários livremente. Já como discurso reportado, consideramos o fato de os 
participantes repetirem a forma verbal usada na pergunta da pesquisadora para veicularem a informação solicitada.

Os resultados mostram que o discurso livre favoreceu a presença da marca de primeira pessoa verbal, já o discurso reportado favoreceu o uso da forma não marcada de terceira pessoa.

A presença da forma marcada de primeira pessoa foi favorecida, tanto em discurso livre, quanto em discurso reportado por falantes que se encontram no ápice do continumm.

Quando buscamos identificar o perfil dos participantes que usaram a forma não marcada logo após uma pergunta em que o verbo também se apresentava na terceira pessoa do singular, como em "você tem filhos?", os dados revelam que esse perfil é composto por falantes que se encontram na base do continum. Dessa forma, discurso reportado é entendido como um gatilho que evidencia uma manifestação baixa de autonomia linguística ocasionada por conta do grau de fluência bilíngue e motivação para o contato (cf. Emmerich,1984).

Tabela 09: Índices gerais referentes à variável social gênero para a marcação ou não-marcação de concordância verbal

\begin{tabular}{|c|c|c|c|c|c|c|c|}
\hline \multirow[t]{2}{*}{ Gênero } & \multicolumn{2}{|c|}{$\begin{array}{l}\text { Presença da marca de pri- } \\
\text { meira pessoa verbal }\end{array}$} & \multicolumn{2}{|c|}{$\begin{array}{l}\text { Presença de forma não } \\
\text { marcada - terceira pessoa } \\
\text { verbal }\end{array}$} & \multicolumn{2}{|c|}{$\begin{array}{l}\text { Presença de forma não } \\
\text { marcada - infinitivo, ge- } \\
\text { rúndio, particípio }\end{array}$} & \multirow[t]{2}{*}{ Total } \\
\hline & $\begin{array}{l}\text { Número de } \\
\text { Ocorrências }\end{array}$ & Frequência & $\begin{array}{l}\text { Número de } \\
\text { Ocorrên- } \\
\text { cias }\end{array}$ & Frequência & $\begin{array}{l}\text { Número de } \\
\text { Ocorrên- } \\
\text { cias }\end{array}$ & Frequência & \\
\hline Feminino & 427 & $74,6 \%$ & 100 & $17,5 \%$ & 45 & $7,9 \%$ & 572 \\
\hline Masculino & 802 & $62,5 \%$ & 341 & $26,5 \%$ & 141 & $11 \%$ & 1284 \\
\hline
\end{tabular}

Conforme já evidenciamos anteriormente, os homens compõem o grupo mais numeroso de nossa amostra. Isso, no entanto, não impede que tenhamos uma base do quanto eles alternam entre as variáveis em estudo e do quanto, comparados individualmente, eles apresentam maior casos de variação que as mulheres.

Chambers (2003) afirma que, em praticamente todos os estudos sociolinguísticos, nos quais há uma amostra de homens e mulheres, estas usam menos variantes estigmatizadas e não-padrão do que os homens do mesmo grupo social, nas mesmas circunstâncias. Os estudos de vários sociolinguistas, como Wolfram (1969), Romaine (1978) e Trudgill (1972) reiteram essa análise. Esses estudos apresentam diferentes objetos de pesquisa, no entanto, mostram-se similares em relação à conclusão dos fatos acerca da variável gênero/sexo, tal como neste estudo, que reitera as interpretações de William Labov (1972).

Tabela 10: Índices gerais referentes à variável social faixa etária para a marcação ou não-marcação de concordância verbal

\begin{tabular}{|l|c|c|c|c|c|c|c|}
\hline \multirow{2}{*}{$\begin{array}{l}\text { Faixa } \\
\text { etária }\end{array}$} & \multicolumn{2}{|l|}{$\begin{array}{l}\text { Presença da marca de pri- } \\
\text { meira pessoa verbal }\end{array}$} & \multicolumn{2}{l|}{$\begin{array}{l}\text { Presença de forma não } \\
\text { marcada - terceira pessoa } \\
\text { verbal }\end{array}$} & $\begin{array}{l}\text { Presença de forma não } \\
\text { marcada - infinitivo, } \\
\text { gerúndio, particípio }\end{array}$ & Total \\
\cline { 2 - 8 } & $\begin{array}{l}\text { Número de } \\
\text { Ocorrências }\end{array}$ & Frequência & $\begin{array}{l}\text { Número de } \\
\text { Ocorrências }\end{array}$ & Frequência & $\begin{array}{l}\text { Número de } \\
\text { Ocorrências }\end{array}$ & Frequência & \\
\hline $\begin{array}{l}\text { Faixa1: } 25 \\
\text { a 40 anos }\end{array}$ & 957 & $73,5 \%$ & 262 & $20,1 \%$ & 83 & $6,4 \%$ & 1302 \\
\hline $\begin{array}{l}\text { Faixa2: } 41 \\
\text { a } 60 \text { anos }\end{array}$ & 277 & $49,5 \%$ & 179 & $32,1 \%$ & 103 & $18,4 \%$ & 559 \\
\hline
\end{tabular}

Ao valermo-nos do fator faixa etária, nossa intenção era buscar determinar se as variantes observadas nos corpora de nosso estudo estão situadas no campo de variação estável ou de mudança linguística. A esse respeito, Tarallo (2007) esclarece que ocorre variação estável quando não se manifestam mudanças entre as faixas etárias. Já a situação de mudança em progresso ocorre quando o uso da variante mais inovadora se manifesta com maior frequência na faixa etária mais jovem, 
sofrendo decréscimo em relação à idade dos informantes mais velhos. Nesse sentido, podemos afirmar que as duas formas alternantes estão em situação de mudança em progresso para a forma marcada de primeira pessoa, que foi privilegiada pelos mais jovens em nosso estudo.

Tabela 11: Índices gerais referentes à variável social escolaridade para a marcação ou não-marcação de concordância verbal

\begin{tabular}{|l|l|l|l|l|l|l|l|}
\hline \multirow{2}{*}{ Escolaridade } & \multicolumn{2}{|l|}{$\begin{array}{l}\text { Presença da marca de pri- } \\
\text { meira pessoa verbal }\end{array}$} & \multicolumn{2}{l|}{$\begin{array}{l}\text { Presença de forma não } \\
\text { marcada - terceira pessoa } \\
\text { verbal }\end{array}$} & $\begin{array}{l}\text { Presença de forma não } \\
\text { marcada - infinitivo, ge- } \\
\text { rúndio, particípio }\end{array}$ & Total \\
\cline { 2 - 7 } & $\begin{array}{l}\text { Número de } \\
\text { Ocorrên- } \\
\text { cias }\end{array}$ & Frequência & $\begin{array}{l}\text { Número de } \\
\text { Ocorrências }\end{array}$ & Frequência & $\begin{array}{l}\text { Número de } \\
\text { Ocorrências }\end{array}$ & Frequência \\
\hline $\begin{array}{l}\text { Ensino Supe- } \\
\text { rior Incom- } \\
\text { pleto }\end{array}$ & 953 & $62 \%$ & 416 & $27 \%$ & 168 & $11 \%$ & 1.537 \\
\hline $\begin{array}{l}\text { Ensino Supe- } \\
\text { rior Com- } \\
\text { pleto }\end{array}$ & 281 & $87 \%$ & 25 & $8 \%$ & 18 & $5 \%$ & 324 \\
\hline
\end{tabular}

Aqui, mais uma vez, os dados revelam que a variável escolaridade exerce grande influência sobre o uso da marca de primeira pessoa verbal, com sensível decréscimo nesse uso por falantes situados na base do continuum.

Diante disso, temos o que segue: o resultado esperado foi alcançado, isto é, quanto maior o nível de escolarização dos falantes, maiores foram as ocorrências que evidenciaram a preservação das marcas de solidariedade entre verbo-sujeito na primeira pessoa do singular. Cabe ainda reiterar que na escola, a forma padronizada é tida como o modelo a ser seguido pelos alunos dentro e fora das salas de aula.

Tabela 12: Índices gerais referentes à variável social localidade para a marcação ou não-marcação de concordância verbal

\begin{tabular}{|l|c|c|c|c|c|c|c|}
\hline LOCALIDADE & \multicolumn{2}{|l|}{$\begin{array}{l}\text { Presença da marca de } \\
\text { primeira pessoa verbal }\end{array}$} & \multicolumn{2}{|l|}{$\begin{array}{l}\text { Presença de forma não } \\
\text { marcada - terceira pes- } \\
\text { soa verbal }\end{array}$} & $\begin{array}{l}\text { Presença de forma não } \\
\text { marcada - infinitivo, } \\
\text { gerúndio, particípio }\end{array}$ & Total \\
\cline { 2 - 8 } & $\begin{array}{c}\text { Número } \\
\text { de Ocor- } \\
\text { rências }\end{array}$ & $\begin{array}{c}\text { Frequên- } \\
\text { cia }\end{array}$ & $\begin{array}{c}\text { Número } \\
\text { de Ocor- } \\
\text { rências }\end{array}$ & $\begin{array}{c}\text { Frequên- } \\
\text { cia }\end{array}$ & $\begin{array}{c}\text { Número } \\
\text { de Ocor- } \\
\text { rências }\end{array}$ & $\begin{array}{c}\text { Frequên- } \\
\text { cia }\end{array}$ & \\
\hline $\begin{array}{l}\text { Comunidade } \\
\text { Vendaval }\end{array}$ & 98 & $49 \%$ & 55 & $28 \%$ & 46 & $23 \%$ & 199 \\
\hline $\begin{array}{l}\text { Comunidade } \\
\text { Santa Inês }\end{array}$ & 78 & $65 \%$ & 34 & $29 \%$ & 7 & $6 \%$ & 119 \\
\hline $\begin{array}{l}\text { Comunidade } \\
\text { Otawari }\end{array}$ & 31 & $37 \%$ & 36 & $43 \%$ & 16 & $19 \%$ & 83 \\
\hline $\begin{array}{l}\text { Comunidade } \\
\text { Paranapara I }\end{array}$ & 28 & $19 \%$ & 83 & $56 \%$ & 37 & $25 \%$ & 148 \\
\hline $\begin{array}{l}\text { Comunidade } \\
\text { Santa Terezinha }\end{array}$ & 64 & $45 \%$ & 56 & $39 \%$ & 23 & $14 \%$ & 143 \\
\hline $\begin{array}{l}\text { Comunidade } \\
\text { Vila Indepen- } \\
\text { dente }\end{array}$ & 234 & $84 \%$ & 36 & $13 \%$ & 8 & $3 \%$ & 278 \\
\hline $\begin{array}{l}\text { Sede de São } \\
\text { Paulo de Oli- } \\
\text { vença }\end{array}$ & 116 & $94 \%$ & 5 & $4 \%$ & 3 & $2 \%$ & 124 \\
\hline $\begin{array}{l}\text { Comunidade } \\
\text { Campo Alegre }\end{array}$ & 233 & $70 \%$ & 5 & $22 \%$ & 26 & $8 \%$ & 334 \\
\hline $\begin{array}{l}\text { Torre da Mis- } \\
\text { são }\end{array}$ & 93 & $62 \%$ & 44 & $29 \%$ & 14 & $9 \%$ & 151 \\
\hline
\end{tabular}




\begin{tabular}{|l|c|c|c|c|c|c|c|}
\hline $\begin{array}{l}\text { São Domingos } \\
\text { II }\end{array}$ & 108 & $91 \%$ & 9 & $8 \%$ & 1 & $1 \%$ & 118 \\
\hline Santa Clara & 64 & $94 \%$ & 3 & $4 \%$ & 1 & $1 \%$ & 68 \\
\hline Nova Galileia & 24 & $77 \%$ & 4 & $13 \%$ & 3 & $10 \%$ & 31 \\
\hline $\begin{array}{l}\text { Bom Jardim do } \\
\text { Passé }\end{array}$ & 59 & $96 \%$ & 5 & $8 \%$ & 0 & 0 & 61 \\
\hline
\end{tabular}

No estudo de Emmerich (1984), considerando-se a hierarquia dos fatores, o fator local de residência do falante se destacou como a variável extralinguística que exerceu maior influência sobre a língua de contato.

Conforme a pesquisadora, o fato responsável por esse resultado foi o caráter multidimensional dessa variável, pois de uma lado, há aldeias localizadas geograficamente próximas aos núcleos de difusão do português e esse fato exerce papel relevante sobre a fluência dos falantes e, de outro, por se localizarem perto desses núcleos de difusão, as aldeias recebiam bastantes visitantes não indios.

Em nosso estudo, os dados revelam que, tal como ocorreu com o fenômeno analisado na seção anterior, os participantes que moram e atuam na comunidade de Paranapara I foram os que mais uso fizeram das variantes não previsíveis no PB, seguidos dos moradores de Otawari, Santa Terezinha, Vendaval e Santa Inês.

Por meio das entrevistas, os professores que atuam nessas aldeias nos relataram que nessas localidades há o predomínio do uso da língua Tikuna. E, em relação à localização geográfica, essas aldeias são distantes dos centros urbanos, para onde os professores se deslocam com uma frequência média. Já os moradores, segundo eles, têm pouco contato com falantes de português

Como já afirmamos anteriormente, ao postularmos o fator localidade, nossa intenção era identificarmos se há localidades cujos moradores apresentam variantes que não ocorrem em outras e se esse fato tinha relação com a localização geográfica e o grau de contato nessas localidades. Fato, em nossa amostra, confirmado.

Tabela 13: Índices gerais referentes à variável social grau de contato para a marcação ou não-marcação de concordância verbal

\begin{tabular}{|c|c|c|c|c|c|c|c|}
\hline \multirow[t]{2}{*}{$\begin{array}{l}\text { Grau de } \\
\text { Contato }\end{array}$} & \multicolumn{2}{|c|}{$\begin{array}{l}\text { Presença da marca de pri- } \\
\text { meira pessoa verbal }\end{array}$} & \multicolumn{2}{|c|}{$\begin{array}{l}\text { Presença de forma não } \\
\text { marcada - terceira pessoa } \\
\text { verbal }\end{array}$} & \multicolumn{2}{|c|}{$\begin{array}{l}\text { Presença de forma não mar- } \\
\text { cada - infinitivo, gerúndio, } \\
\text { particípio }\end{array}$} & \multirow[t]{2}{*}{ Total } \\
\hline & $\begin{array}{l}\text { Número de } \\
\text { Ocorrências }\end{array}$ & $\begin{array}{l}\text { Frequên- } \\
\text { cia }\end{array}$ & $\begin{array}{l}\text { Número de } \\
\text { Ocorrências }\end{array}$ & Frequência & $\begin{array}{l}\text { Número de } \\
\text { Ocorrências }\end{array}$ & Frequência & \\
\hline BAIXO & 69 & $25 \%$ & 125 & $46 \%$ & 80 & $29 \%$ & 274 \\
\hline MÉDIO & 608 & $65 \%$ & 246 & $26 \%$ & 82 & $9 \%$ & 936 \\
\hline ALTO & 524 & $84 \%$ & 70 & $11 \%$ & 25 & $4 \%$ & 619 \\
\hline
\end{tabular}

Os resultados concernentes à variável social grau de contato em nossa amostra reiteram os resultados alcançados em estudos que também investigam os resultados do contato linguístico entre os indígenas, como os de Emmerich (1984), os trabalhos elencados em Roncarati \& Mollica (1997) e o de Loureiro (2005). Nesses trabalhos, assim como em nosso estudo, os falantes mais fluentes são aqueles que apresentam uma proximidade linguística com a língua-alvo. São também os que mais frequentemente têm contato com os falantes nativos de $\mathrm{PB}$ e se deslocam das aldeias para centros urbanos.

Em nosso estudo, os falantes de grau alto apresentaram uma frequência de $84 \%$ dos casos de marcação de concordância do verbo com a primeira pessoa do singular, ao passo que os falantes de grau baixo apresentam uma frequência de $25 \%$, ou seja, mais distante linguisticamente do padrão da língua-alvo. 
Tabela 14: Índices gerais referentes à variável social fluência para a marcação ou não-marcação de concordância verbal

\begin{tabular}{|l|c|c|c|c|c|c|c|}
\hline $\begin{array}{l}\text { Faixa de } \\
\text { fluência }\end{array}$ & \multicolumn{2}{|l|}{$\begin{array}{l}\text { Presença da marca de } \\
\text { primeira pessoa verbal }\end{array}$} & \multicolumn{2}{l|}{$\begin{array}{l}\text { Presença de forma não } \\
\text { marcada - terceira pes- } \\
\text { soa verbal }\end{array}$} & $\begin{array}{l}\text { Presença de forma não } \\
\text { marcada - infinitivo, ge- } \\
\text { rúndio, particípio }\end{array}$ & Total \\
\cline { 2 - 8 } & $\begin{array}{l}\text { Número de } \\
\text { Ocorrências }\end{array}$ & $\begin{array}{l}\text { Frequên- } \\
\text { cia }\end{array}$ & $\begin{array}{l}\text { Número de } \\
\text { Ocorrências }\end{array}$ & $\begin{array}{l}\text { Frequên- } \\
\text { cia }\end{array}$ & $\begin{array}{l}\text { Número de } \\
\text { Ocorrências }\end{array}$ & $\begin{array}{l}\text { Fre- } \\
\text { quência }\end{array}$ & \\
\hline Faixa 1 & 177 & $40 \%$ & 173 & $39 \%$ & 89 & $20 \%$ & 439 \\
\hline Faixa 2 & 293 & $61 \%$ & 148 & $31 \%$ & 37 & $8 \%$ & 478 \\
\hline Faixa 3 & 107 & $53 \%$ & 64 & $31 \%$ & 32 & $16 \%$ & 203 \\
\hline Faixa 4 & 470 & $86 \%$ & 49 & $9 \%$ & 27 & $5 \%$ & 546 \\
\hline Faixa 5 & 183 & $95 \%$ & 8 & $4 \%$ & 1 & $0,5 \%$ & 192 \\
\hline
\end{tabular}

Como se esperava, os dados revelam que os falantes das faixas mais altas do continuum realizam, com um alto índice ( $86 \%$ e $95 \%$ ), a concordância verbal de primeira pessoa do singular, enquanto os falantes da faixa mais baixa do continuum realizam essa concordância com índice menor (40\%). Tal fato atesta a validade das faixas de fluência que estabelecemos em nosso estudo, pois os falantes das faixas 4 e 5 demonstram uma elevada fluência bilíngue, com as menores ocorrências de transferência de traços da L1 na variedade de português que eles falam; já os falantes da faixa 1 apresentam uma fluência bilíngue marcada por traços acentuados de transferência da L1 nos níveis estudados; por outro lado, os falantes das faixas 2 e 3 apresentam um fluência bilíngue que oscila entre transferência de L1, porém menos que os da faixa 1, e incorporações de padrões da línguaalvo (Português), também, menos que os das faixas 4 e 5 .

\section{Considerações finais}

Neste artigo, apresentamos um estudo da variação no Português Tikuna, com base na análise das variáveis sociais e linguísticas no uso de um fenômeno morfossintático e um fonético. A partir dos dados apresentados ao longo do trabalho, podemos inferir que o objetivo da pesquisa de analisar fatores sociais e linguísticos que estariam condicionando a variação quanto ao uso da concordância na primeira pessoa do singular (P1) e ao uso de /s/ em posição de onset foi alcançado.

No que diz respeito à variação de /s/ em posição de onset, a escolha deste aspecto variável se deu por conta de ele não ser objeto de um número considerável de pesquisas que tratam da variação de /s/ no PB. A posição mais investigada é a coda, não onset, tendo em vista que nessa posição, a variação é neutralizada, fato que não ocorre no Português Tikuna, tendo em vista que nessa variedade do $\mathrm{PB}$, identificamos outro comportamento de /s/ em posição de onset, o qual se mostra como alofone em distribuição complementar. Para descrever e analisar a variação da fricativa /s/ em posição de onset na fala dos participantes da pesquisa, foram delimitados os seguintes fatores condicionadores (ou inibidores) da variação em estudo: a) fator linguístico: contexto seguinte - vogal alta [i]; vogal média-alta [ $\varepsilon]$; vogal média-baixa [e] e vogal baixa [a]; b) fatores sociais: gênero, faixa etária, escolaridade, localidade e grau de fluência. A segunda vogal que mais favoreceu a palatalização da fricativa, acompanhada de ligeira retroflexão, foi a vogal baixa [a]. O fato de, tanto a vogal média-baixa quanto a vogal baixa terem contribuído para a produção dessa variante indica que o ponto de articulação baixo favorece que a articulação da fricativa ocorra com recuo. Já em relação à variante [ts] ], a vogal alta foi que favoreceu a ocorrência dessa africação. Em relação aos fatores sociais, nossos achados confirmaram aqueles já postulados no campo da Sociolinguística quanto à idade, escolaridade, sexo; no campo do Contato Linguístico confirmamos fatores como lugar de origem, graus de fluência e intensidade do contato.

Quanto à variação de concordância na primeira pessoa do singular (P1), temos as seguintes considerações: na tese de Emmerich (1984), a pesquisadora defende que a variação entre a primeira pessoa verbal e a forma flexionada de terceira pessoa singular é característica de línguas em contato e que tal fenômeno marca o português xinguano, considerado como pidgin pela linguista. Já nos

https://periodicos.unifap.br/index.php/letras

Macapá, v. 10, n. 1, $1^{\circ}$ sem., 2020 
trabalhos de Ferreira (1994), Baxter e Lucchesi (1997), encontramos a defesa de que essa variação entre a primeira pessoa verbal e a forma flexionada de terceira pessoa singular é característica de línguas em contato, sendo fruto da transmissão linguística irregular e utilizada como um dos argumentos em favor da existência de crioulização no português brasileiro. Por outro lado, Naro e Scherre (2007) rechaçam os estudos que utilizam a neutralização entre $1^{a}$ e $3^{a}$ pessoa do singular como argumento para validar a hipótese de crioulização no português brasileiro, bem como rechaçam os estudos que usam essa neutralização como argumento para evidenciar a influência de processos de aquisição do português como segunda língua ou como língua estrangeira. De acordo com os autores, "os paradigmas verbais da língua portuguesa codificada pelas gramáticas tradicionais - normativas ou não- estão repletos de neutralização de $1^{\text {as }}$ e $3^{\text {as }}$ pessoas do singular, não interpretadas como falta de concordância". (NARO; SCHERRE, 2007, p. 93). Naro e Scherre (2007) realizaram um verdadeiro garimpo linguístico na tentativa de identificar traços linguísticos no português europeu não padrão que têm sido considerados, em alguns estudos sobre o contato de línguas, como exclusivos do português popular brasileiro.

Em nosso estudo, o fato de ocorrerem, na fala dos professores Tikuna, variantes concorrentes com a regra de concordância de primeira pessoa do singular é fruto do estágio aquisitivo em que se encontram esses falantes de português como segunda língua e essa variação faz parte da variedade de Português Tikuna. Contrariamente a que outros estudos postulam, de que a regra de concordância de primeira pessoa, na atualidade é categórica no PB (cf. Emmerich, 1984; Lucchesi e Baxter, 2009), inclusive em comunidades rurais, em nosso estudo, tal postulação é refutada e marca a variedade do Português Tikuna, cujos falantes apresentam diferentes graus de fluência.

\section{Referências}

AMADO, R.S. O português étnico dos povos Timbira. PAPIA, São Paulo, 25(1), jan/jun. 2015, pp. 103-119.

BAXTER, A. N. A Concordância de Número. In: LUCCHESI, D.; BAXTER, A.N.; RIBEIRO, I. (Orgs.). O português afro-brasileiro. Salvador: EDUFBA, 2009. pp. 269-293

. \&LUCCHESI, D. A relevância dos processos de pidgnização e crioulização na formação da língua portuguesa no Brasil. Estudos linguísticos e literários, Salvador, n. 19, mar.1997.

BENAYON, A.R. Aquisição das fricativas no Português Brasileiro: propriedades distribucionais e variação. Tese de Doutorado em Linguística. Rio de Janeiro: UFRJ, Faculdade de Letras, 2010.

BONIFÁCIO, L.P.S. Contato Linguístico Tikuna-Português no Alto Solimões-Amazonas: um Estudo sobre a Variedade de Português Falada por Professores Tikuna. Tese (Doutorado em Linguística), UFRJ, 2019.

CALAZANS, P. C. A marcação da concordância verbal de terceira pessoa do plural no Português de contato dos Guarani do Espírito Santo. Tese (Doutorado em Linguística). Rio de Janeiro: Universidade Federal do Rio de Janeiro, 2018.

CHAMBERS, J.K. Sociolinguistic theory. 2nd. Edition. Oxford, UK: Blackwell, 2003.

CHRISTINO, B. P. Concordância de gênero em sintagmas nominais do Português Huni-Kuin. PAPIA, São Paulo, 25(1), Jan/Jun 2015, pp. 77-102.

CUNHA, C. S.; SILVA, J. Variação entoacional nos enunciados intrrrogativos. In: ABRAÇADO, J.; MARTINS, M. A. (Orgs.). Mapeamento sociolinguístico do português brasileiro. São Paulo: Contexto, 2015.

DUARTE, M. E. L. A perda do princípio "evite pronome" no Português Brasileiro. Tese (Doutorado em Linguística) - Instituto de Estudos da Linguagem, Universidade Estadual de Campinas: Campinas, 1995.

. Do pronome nulo ao pronome pleno: a trajetória do sujeito no português do Brasil. In: ROBERTS, I.; KATO; M. A. (Orgs.). Português Brasileiro: uma viagem diacrônica. Ed. da UNICAMP: Campinas, 1993, pp. 107-128. 
EMMERICH, C. A Língua de Contato no Alto Xingu. Origem, Forma e Função. Tese de Doutorado em Linguística. Rio de Janeiro: UFRJ, Faculdade de Letras, 1984.

; PAIVA, M. C. Português xinguano: origem e trajetória. In: CARVALHO, A. M. (Org.). Português em contato. Madrid: Iberoamericana, 2009. pp. 153-164.

FERREIRA, C. da S. Remanescentes de um falar crioulo brasileiro. Diversidade do português do Brasil. Estudos da dialetologia rural e outros. Salvador: Centro Editorial e Didático, Universidade Federal da Bahia, 1994.

FERREIRA, M. Descrição de aspectos da variante étnica usada pelos Parkatejê. DELTA. Vol. 21, n 1 , São Paulo, 2005, pp. 1-21.

GOMES, C. A. Processos variáveis e aquisição de preposição em L2. In: RONCARATI, C.; MOLLICA, M. C. (orgs.). Variação e aquisição. Rio de Janeiro: Tempo Brasileiro, 1997, pp. 103-116. . Aquisição do subsistema de preposições no português em contato no Xingu. In: CARVALHO, A. M. (Org.). Português em contato. Madrid: Iberoamericana, 2009, pp.165-176.

; BRESCANCINI, C.R.; MONARETTO, V.O. Variação sonora. In: MARTINS, M.A; ABRAÇADO, J. (Orgs.). Mapeamento sociolinguístico do português brasileiro. São Paulo: Contexto, 2015.

LABOV, W. Sociolinguistic patterns. Philadelphia: University of Pennsylvania Press, 1972. Padrões sociolinguísticos. (Tradução Marcos Bagno, Marta Maria Pereira Scherre e Caroline Cardoso) São Paulo: Parábola Editorial, 2008 [1972].

LEITE, Y.; CALLOU, D. Como falam os brasileiros. Rio de Janeiro: Jorge Zahar Ed., 2002.

LOUREIRO, F. C. Aspectos da Pluralização no Português de Contato do Alto Xingu. Tese (Doutorado). Rio de Janeiro: Universidade Federal do Rio de Janeiro, 2005.

OMENA, N.P. A referência à primeira pessoa do plural: variação ou mudança? In: PAIVA; M. da C.; DUARTE, M.E.L. (Orgs.). Mudança linguística em tempo real. Rio de Janeiro: Contra Capa, 2003, pp. 63-80.

PAIVA, M. da C. A variável gênero/sexo. In: MOLLICA, M. C.; BRAGA, M. L. (Orgs.). Introdução à Sociolinguística: o tratamento da variação. 4 ed. São Paulo: Contexto, 2013, pp. 33 - 42.

Variação e aquisição do traço de sonoridade. In: RONCARATI, C.; MOLLICA, M. C. (orgs.). Variação e aquisição. Rio de Janeiro: Tempo Brasileiro, 1997, pp. 15-32.

RIBEIRO, C. M. R. Contato Linguístico e a Concordância de Número no Sintagma Nominal no português de Oiapoque/AP. Tese (Doutorado em Linguística). Rio de Janeiro: Universidade Federal do Rio de Janeiro, 2018.

RODRIGUES, A. D. Línguas indígenas: 500 anos de descobertas e perdas. D.E.L.T.A. São Paulo, 1993.

ROMAINE, S. Postvocalic / $r$ / in Scottish English: sound change in progress? Sociolinguistic Patterns in British English, ed. Peter Trudgill. London: Edward Arnold. 1978.

RONCARATI, C.; MOLICA, M. C. (Orgs.). Variação e Aquisição. Rio de Janeiro: Tempo Brasileiro, 1997.

SCHERRE, M. M. P. A regra de concordância de número no sintagma nominal em Português. Dissertação (Mestrado). Rio de Janeiro: PUC, 1978.

- Aspectos da concordância de número no português do Brasil. Revista Internacional de Língua Portuguesa (RILP) - Norma e Variação do Português. Associação das Universidades de Língua Portuguesa. 12:37-49. dez. de 1994.

Paralelismo linguístico. Revista de Estudos da Linguagem, Belo Horizonte, v. 7, n. 2, 1998, pp. $29-59$.

, NARO. A. J. A concordância de número no português do Brasil: um caso típico de variação inerente. In: HORA, D. (Org.). Diversidade Linguística no Brasil. João Pessoa: Ideia, 1997. pp. $93-114$.

SCHERRE, M. M. P; DIAS, E. P.; ANDRADE, E.; MARTINS, G. F. Variação dos pronomes "tu" e "você". In: MARTINS, M.A.; ABRAÇADO, J. (Orgs.). Mapeamento sociolinguístico do português brasileiro. São Paulo: Contexto, 2015, pp. 133-172.

https://periodicos.unifap.br/index.php/letras

Macapá, v. 10, n. 1, $1^{\circ}$ sem., 2020 
SCHERRE, M. M. P.; NARO, A. J.; CARDOSO, C. R. O papel do tipo de verbo na concordância verbal no português brasileiro. DELTA, São Paulo, v. 23, n. esp., 2007, pp. 283 $-317$.

TARALLO, F. A pesquisa sociolinguística. 8 ed. São Paulo: Ática, 2007.

TRUDGILL, P. Sex, covert prestigie, and linguistic change in the urban British English of Norwick. Language in Society, 1972.

VIEIRA, S. R.; BRANDÃO, S. F. Tipologia de Regras Linguísticas e Estatuto das Variedades/Línguas: a Concordância em Português. Linguística, v. 30 (2), 2014, pp. 81-112.

VOTRE, S. J. Relevância da variável escolaridade. In: MOLLICA, M. C.; BRAGA, M. L. (Orgs.). Introdução à Sociolinguística: o tratamento da variação. 4.ed. São Paulo-SP: Editora Contexto, 2013, pp.51-57.

WEINREICH, U. Languages in contact: Finding and problems. New York, Linguistic Circle of New York, 1953.

WOLFRAM, W. Dialects in squirrel monkeys: vocalizations of the Roman archtype. Folia Primatologica, 1969. 